\title{
EDITORIAL
}

\section{Understanding and making practice explicit}

This issue contains four, on the face of it, quite different papers, but on looking a little closer there are a number of interesting themes running through them that illustrate some of the key methodological and theoretical issues that e-learning researchers are currently struggling with; central to these is the issue of how do we understand and make practice explicit?

Goodyear, de Laat and Lally open the issue with a paper describing the use of patterns and pattern language as a means of articulating practice, and in particular providing a mediating bridge to make sense of the complex environment within which modern education takes place. They argue that 'the increasing complexity of learning situations will require and help people to become more design-savvy', and present patterns and pattern language as a means of facilitating this. What is appealing to me about this approach is the way in which patterns might provide a valuable way of capturing practice; however, it raises issues about how (or whether) educational practice can be 'codified' and whether a shared, common, meaningful understanding can be achieved. It seems that this paper goes to the heart of one of the 'holy grails' of current e-learning research, namely the search for mechanisms to provide more useful support to practitioners to create more pedagogically informed learning activities. This is certainly evident in many current funding initiatives, not least the JISC (Joint Information Systems Committee)'s e-pedagogy programme.

In a different way Phil Levy is also looking to elicit practice. She presents a pedagogical framework for process support in networked learning, using a case study analysis of learners' experiences coupled with a critical evaluation of educational practice. She contents that practitioners do not fully understand the relationship between their educational designs and their outcomes - a sentiment that seems to echo some of the driving motivation for Goodyear et al.'s work. The model she presents for 'capturing' practice and bridging this gap, however, is quite different to that proposed by Goodyear et al. Her framework identifies four areas for integrated process support (orientation, communication, socialisation and organisation) within two design/action phases-induction and on-going support. The relationship between these she suggests is in-parallel and interconnected rather than sequential.

Alsop and Tompsett consider the methodological issues surrounding qualitative analysis, and provide a detailed critical reflection on one particular approachphenomenography. They argue that too often methodological positions are adopted in e-learning research without clear justification or awareness of particular weaknesses. 


\section{Editorial}

Finally, Jones and Cooke return to the theme of qualitative analysis by describing two case studies of online group communication and collaboration, arguing that this approach can lead to an opening up of a 'window into learning' providing new insights into complex problem-solving and thinking processes. Again this offers an alternative strategy to that put forward by Levy as a means of understanding and improving our own practice. One of their conclusions is that "looking through this "window" enables us to concentrate our assessment more closely on the process of task completion, rather than focusing solely on the end product'.

For me, a host of questions arise from reading these papers in terms of the methodological and theoretical implications they raise. Also it seems to me that we are now seeing evidence of the ways in which, as a community of e-learning researchers, we are beginning to diverge and adopt different theoretical and methodological positions. It will be interesting in time to see what differences arise as a result and how they help us address some of the core questions and issues in our area.

Gráinne Conole The Open University, UK 